\title{
Atresia of urethra
}

INSERM

\section{Source}

INSERM. (1999). Orphanet: an online rare disease and orphan drug data base. Atresia of urethra. ORPHA:105

Atresia of the urethra is a rare congenital bladder outlet obstruction, a fetal lower urinary tract obstruction (fetal LUTO), that is usually fatal. Unless there is some other egress for the urine to escape the bladder, such as patent urachus or anuro-rectal communication, these lesions are not compatible with renal development. 